\title{
Phylogenetic relationships of snails of the genera Oncomelania and Tricula inferred from the mitochondrial $12 \mathrm{~S}$ rRNA gene
}

\author{
MUNEHIRO OKAMOTO ${ }^{1}$, CHIN-TSON LO ${ }^{2}$, WILFRED U. TIU ${ }^{3}$, DONGCHUAN QUI $^{4}$, \\ PINARDI HADIDJAJA ${ }^{5}$, SUCHART UPATHAM ${ }^{6}$, HIROMU SUGIYAMA $^{7}$, \\ TAKAHIRO TAGUCHI ${ }^{8}$, HIROHISA HIRAI $^{9}$, YASUHIDE SAITOH ${ }^{10}$, \\ SHIGEHISA HABE ${ }^{11}$, MASANORI KAWANAKA ${ }^{7}$, MIZUKI HIRATA ${ }^{12}$ AND \\ TAKESHI AGATSUMA ${ }^{13 *}$ \\ Accepted 28, February, 2002
}

\begin{abstract}
The Schistosoma japonicum group and S. sinensium utilize intermediate snail hosts belonging to the genera Oncomelania and Tricula (Gastropoda: Pomatiopsidae). In the present study, partial sequences of the mitochondrial $12 \mathrm{~S}$ rRNA gene from 7 subspecies of $O$. hupensis, two species of Tricula (T. bollingi and T. humida) and $O$. minima were examined to infer a phylogeny for these. Nucleotide differences among subspecies of $O$. hupensis were less than $6.5 \%$ and among species from different genera, 10-12\%. The phylogenetic tree obtained in this study indicates that $O$. hupensis subspecies fell into four distinct clades; that is, $O$. $h$. quadrasi from the Philippines, $O . h$. lindoensis from Indonesia, $O . h$. hupensis from Yunnan, China and the remaining 5 subspecies $(O . h$. hupensis from other parts of China, $O . h$. robertsoni from China, $O$. $h$. formosana from Taiwan, $O . h$. chiui from Taiwan and $O$. h. nosophora from Japan). The phylogenetic tree also showed that $O$. minima was placed as sister to all of the subspecies of $O$. hupensis. Possible evolutionary relationships among the snail hosts were discussed.
\end{abstract}

Key Words: Oncomelania, Tricula, mitochondrial DNA, 12S rRNA gene, phylogenetic tree

\section{INTRODUCTION}

Species of Schistosoma have been placed in a number of groups based on, amongst other things, egg morphology and/or geographical distribution (Rollinson and Southgate, 1987). For example, African schistosomes of the S. mansoni and $S$. haematobium groups develop in pulmonate snails of the family Planorbidae, while the oriental species, namely the S. japonicum group (S. japonicum, S. mekongi, S. malayensis) and $S$. sinensium, utilize snails belonging to the family Pomatiopsidae. Pulmonate snails belong to the sub- class Pulmonata, while pomatiopsids belong to the subclass Caenogastropoda. These two subclasses diverged a long time ago (Davis, 1980). Generally, specificity for an intermediate host in the genus Schistosoma is high (Rollinson and Southgate, 1987). So the phylogeny of these intermediate host snails seems to be very important when the evolution of the schistosome is traced.

Schistosoma japonicum is widely distributed throughout East Asia, China and Japan, and the intermediate host is Oncomelania hupensis. Since $O$. hupensis shows geographical variation in morphology, many subspecies have

\footnotetext{
${ }_{1}$ Department of Laboratory Animal Science, School of Veterinary Medicine, Faculty of Agriculture, Tottori University, Tottori 680-8553, Japan.

2 Department of Parasitology, National Yang-Ming University, Taipei, Taiwan, R.O.C.

3 Department of Parasitology, College of Public Health, University of Philippines, Manila, Philippines

4 Department of Schistosomiasis, Sichuan Institute of Parasitic Diseases, Chengdu 610041, China

5 Department of Parasitology, Faculty of Medicine, University of Indonesia, Jakarta, Indonesia

${ }^{6}$ Department of Biology, Faculty of Science, Mahidol University, Bangkok, Thailand

7 Department of Parasitology, National Institute of Infectious diseases, Tokyo, Japan

8 Department of Anatomy, Faculty of Medicine, Kochi Medical School, Nankoku, Kochi 783-8505, Japan

9 Department of Population Genetics, Primate Research Institute, Kyoto University, Inuyama 484-8506, Japan

${ }^{10}$ Department of Parasitology, Faculty of Veterinary Medicine, Azabu University, Kanagawa, Japan

${ }^{11}$ Department of Parasitology, Faculty of Medicine, Fukuoka University, Fukuoka, Japan

${ }^{12}$ Department of Parasitology, Faculty of Medicine, Kurume University, Kurume, Japan

${ }^{13}$ Department of Environmental Health Science, Faculty of Medicine, Kochi Medical School, Nankoku, Kochi 783-8505, Japan

*Corresponding author: T. Agatsuma; Phone/Fax: +81888802535; E-mail:
} 
been described (Davis et al., 1995). Geographical variation is so great that some researchers prefer to regard the subspecies as independent species (Woodruff et al., 1988; Nihei et al., 1998). In the present study, phylogenetic relationships of the snail hosts of S. japonicum, O. hupensis, and other related species of Oncomelania and Tricula were studied using the mitochondrial $12 \mathrm{~S}$ rRNA gene.

\section{MATERIALS AND METHODS}

\section{Snail samples}

Sixteen isolates of $O$. hupensis, belonging to 7 subspecies, were examined. We also examined O. minima, T. bollingi and T. humida. The geographical origins and locations of species or subspecies used in this study are shown in Table 1 and Fig. 1.

Preparation of DNA

Genomic DNA from each snail sample was extracted using Easy-DNA Kit (Invitrogen, USA). DNA extracted by this kit contained an inhibitor for PCR, and this inhibitor could not be removed by phenol/chloroform extraction or commercially available spin column etc. So DNA was purified by $0.5 \%$ agarose gel electrophoresis with $0.5 \mathrm{X}$ Trisboric EDTA buffer. After electrophoresis, high molecular weight DNA was cut off with agarose gel and extracted by QIAEX II Gel Extraction Kit (Qiagen, Germany).

Amplification and sequencing of DNA

Purified genomic DNA was used as a template for amplification of DNA fragments by the polymerase chain reac-

Table 1. Geographical origins of subspecies or species of Oncomelania and Tricula examined.

\begin{tabular}{lll}
\hline \multicolumn{1}{c}{ subspecies or species } & \multicolumn{1}{c}{ Location } & \multicolumn{1}{c}{ Country } \\
\hline Oncomelania hupensis hupensis & Anhui & China \\
O. h. hupensis & Hunan & China \\
O. h. hupensis & Hubei & China \\
O. h. hupensis & Yunnan & China \\
O. h. robertsoni & Sichuan & China \\
O. h. formosana & Kaohsiung & Taiwan \\
O. h. formosana & Shuili & Taiwan \\
O. h. formosana & Yilan & Taiwan \\
O. h. chiui & Shimen & Taiwan \\
O. h. nosophora & Kofu & Japan \\
O. h. nosophora & Kurume & Japan \\
O. h. lindoensis & Sulawesi & Indonesia \\
O. h. quadrasi & Mindoro & Philippines \\
O. h. quadrasi & Bohor & Philippines \\
O. h. quadrasi & Asuncion & Philippines \\
O. h. quadrasi & Digos & Philippines \\
O. minima & Sado & Japan \\
Tricula bollingi & Fang & Thailand \\
T. humida & Sichuan & China \\
\hline
\end{tabular}

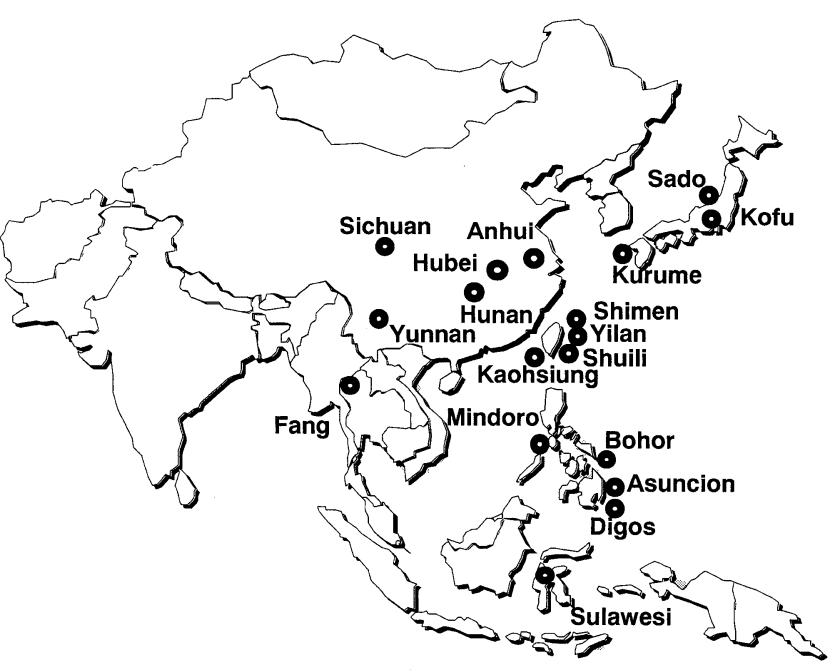

Fig. 1. Geographical locations of species or subspecies of Oncomelania and Tricula used in this study.

tion (PCR). Amplification of a part of the mitochondrial 12 $\mathrm{S}$ rRNA gene was carried out using universal primers (Kocher et al., 1989). The sequences of the primers were as follows: L1091; 5'-AAA AAG CTT CAA ACT GGG ATT AGA TAC CCC ACT AT-3' and H1478; 5'-TGA CTG CAG AGG GTG ACG GGC GGT GTG T-3'. PCR was performed using Ampli Taq DNA Polymerase (Perkin Elmer, USA) according to the manufacturer's instructions. After an initial denaturation step $\left(94^{\circ} \mathrm{C}\right.$ for 3 minutes) there were 30 cycles of denaturation at $94^{\circ} \mathrm{C}$ for $30 \mathrm{sec}$, annealing at $50^{\circ} \mathrm{C}$ for $30 \mathrm{sec}$ and extension at $72^{\circ} \mathrm{C}$ for $1 \mathrm{~min}$. PCR products were purified with QIAquick-spin PCR purification Kit (Qiagen). Purified double-stranded PCR products were directly sequenced with the same primers as those of PCR from both ends using Dye Terminator Cycle Sequencing FS Ready Reaction Kit and a Model 377A DNA sequencer (Perkin Elmer).

Phylogenetic analyses

DNA sequence data were aligned using the CLUSTAL $\mathrm{W}$ computer program. The evolutionary distances were computed by Kimura's two-parameter method (Kimura, 1980), and the phylogenetic tree was constructed by the neighbor-joining method using the neighbor-joining computer program in the PHYLIP 3.5 phylogeny package (Felsenstein, 1993). The tree was evaluated using the bootstrap test based on 1,000 resampling. A sequence from Littorina littorea was used for the outgroup (Rumbak et al., 1994).

\section{RESULTS AND DISCUSSION}

Using this primer pair, fragments of 365 to $368 \mathrm{bp}$ were amplified in this study. Sequences and partial alignments of $12 \mathrm{~S}$ rRNA gene are shown in Fig. 2. The maxi- 
OhcShimen OhfKaohsiung OhfShuili Ohfyilan Ohhanhui OhhHubei

OhhHunan OhhYunnan Ohlsulawesi OhnKoufu OhnKurume OhqAssuncion ohqBohor

OhqDigos

OhqMindro Ohqsorsogon Ohrsichuan Ominimasado TbollingiFang Thumidasichuan Llittorea

OhcShimen OhfKaohsiung OhfShuili OhfYilan Ohhanhui OhhHubei OhhHunan OhhYunnan Ohlsulawesi ohnKoufu OhnKurume OhqAssuncion OhqBohor OhqDigos ohquindro ohqsorsogon Ohrsichuan Ominimasado TbollingiFang Thumidasichuan Ilittorea

OhcShimen OhfKaohsiung OhfShuili

OhfYilan Ohhanhui OhhHubei

OhhHunan OhhYunnan Ohlsulawesi OhnKoufu

OhnKurume OhqAssuncion

OhqBohor

OhqDigos

Ohquindro ohqsorsogon Ohrsichuan Ominimasado

Tbollingifang

Thumidasichuan 161 : Llittorea

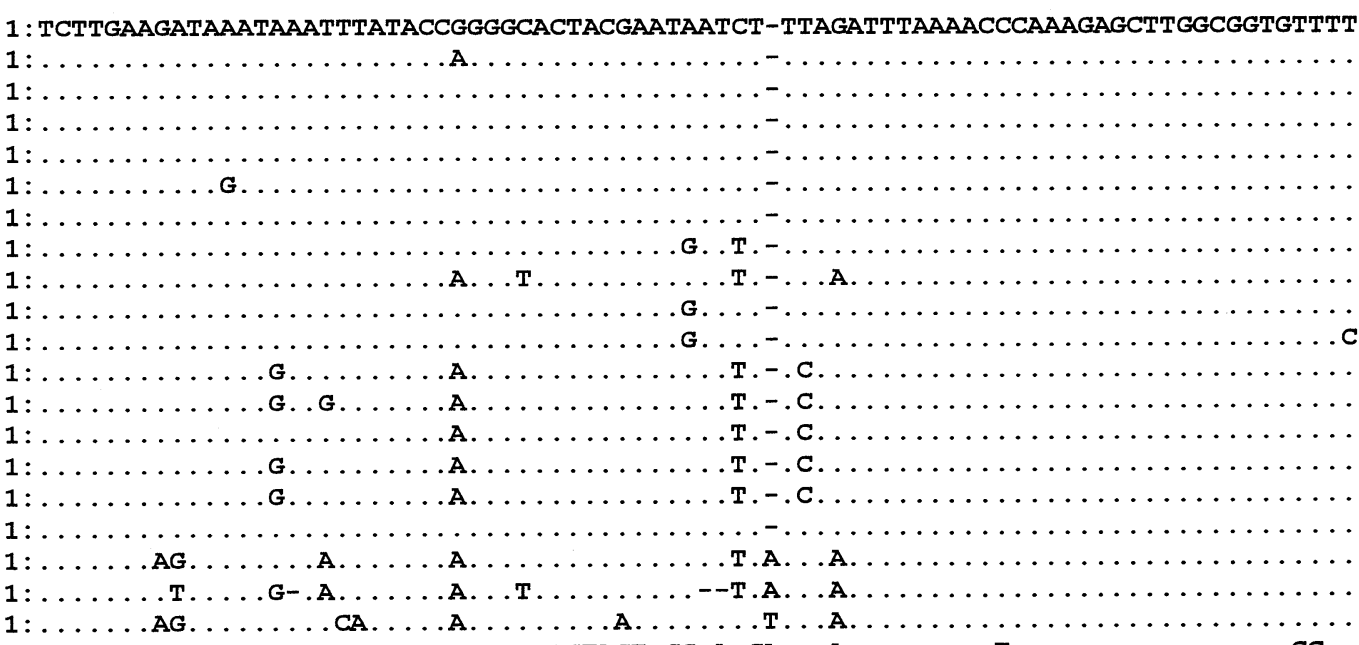

$1: \ldots$ AG. TG. . . . . TATACGAGAGTACT. CG. A. CA- . A.
CC. .

81 : AGACTATTTAGGGGACTTGTTTCATAATCGATAATCCACGAGATACCTAACCTTCTTTTGTAATCAGTATGTATACCGT

\begin{tabular}{|c|}
\hline 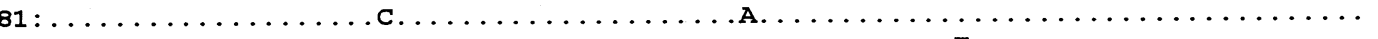 \\
\hline 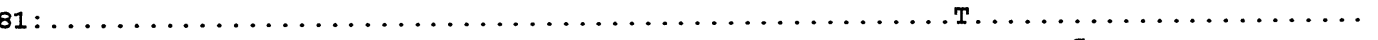 \\
\hline 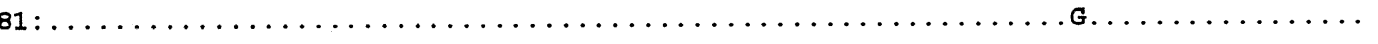 \\
\hline$\cdots \cdots \cdots \cdots$ \\
\hline 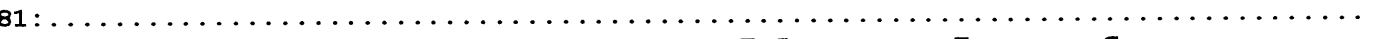 \\
\hline 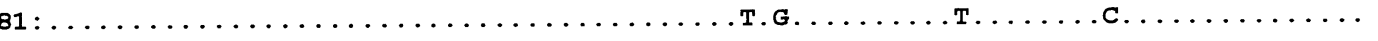 \\
\hline 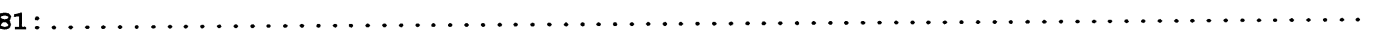 \\
\hline 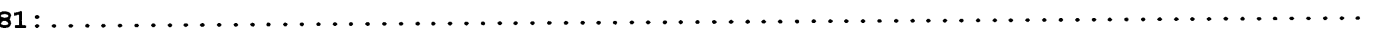 \\
\hline 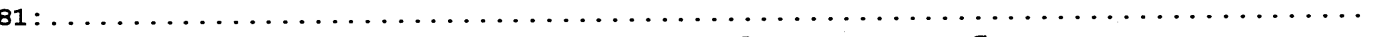 \\
\hline 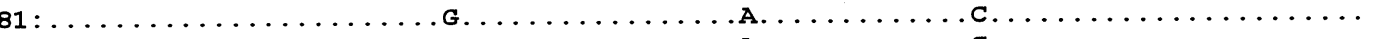 \\
\hline 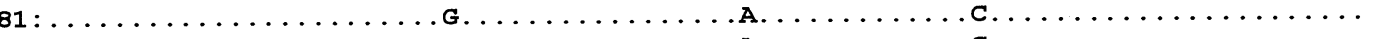 \\
\hline 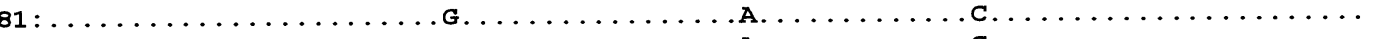 \\
\hline 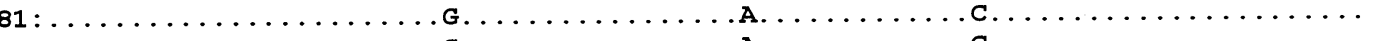 \\
\hline 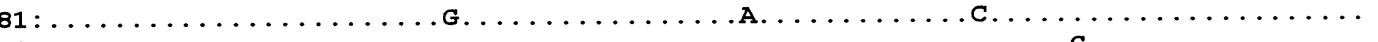 \\
\hline 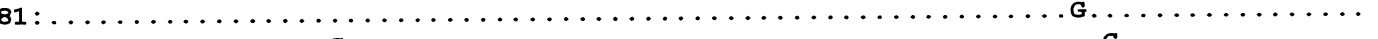 \\
\hline$\ldots$ G................ \\
\hline 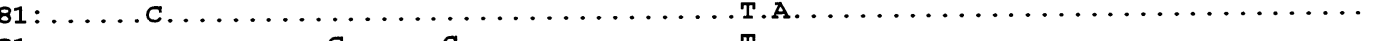 \\
\hline 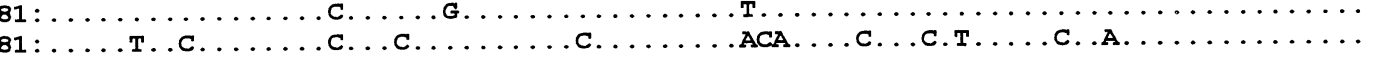 \\
\hline
\end{tabular}

161 : TGTCGTCAGGTAACTTTTTAAAATAAAAAAGTTA-GCGAAAAAGCCATAAGCTTACACGTCAAATCAAGGTACAGCCTAT

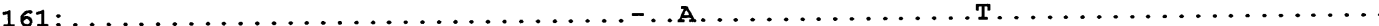

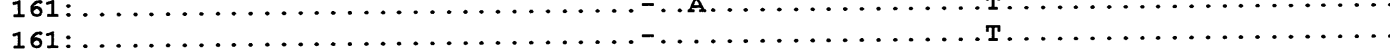

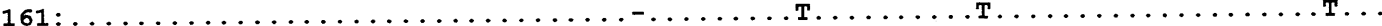

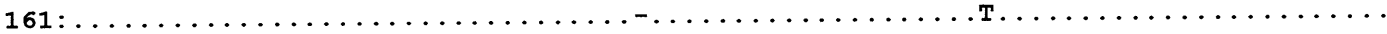

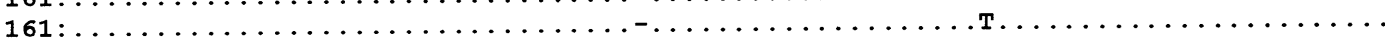

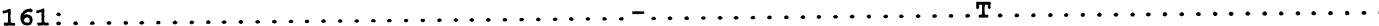

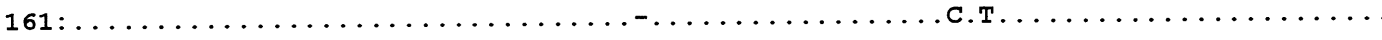

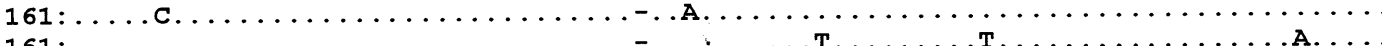

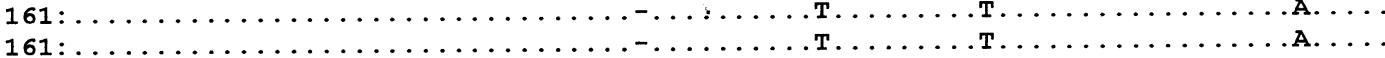

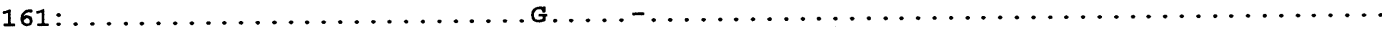

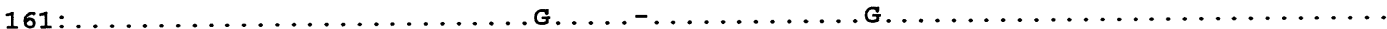

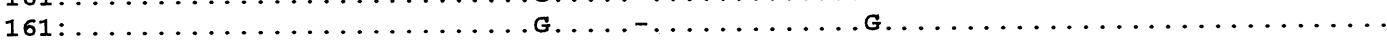

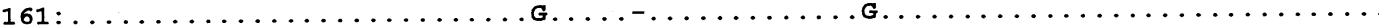

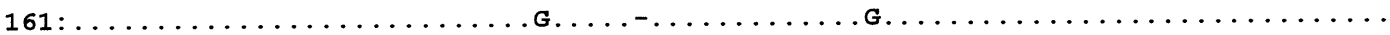

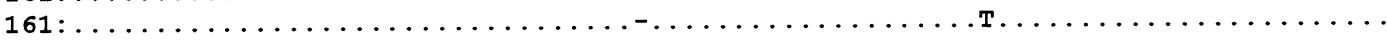

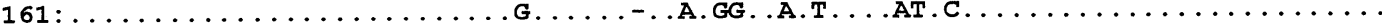

$161: \ldots \ldots \ldots \ldots \ldots \ldots \ldots \ldots \ldots$.

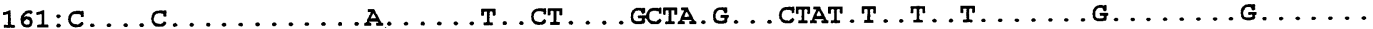




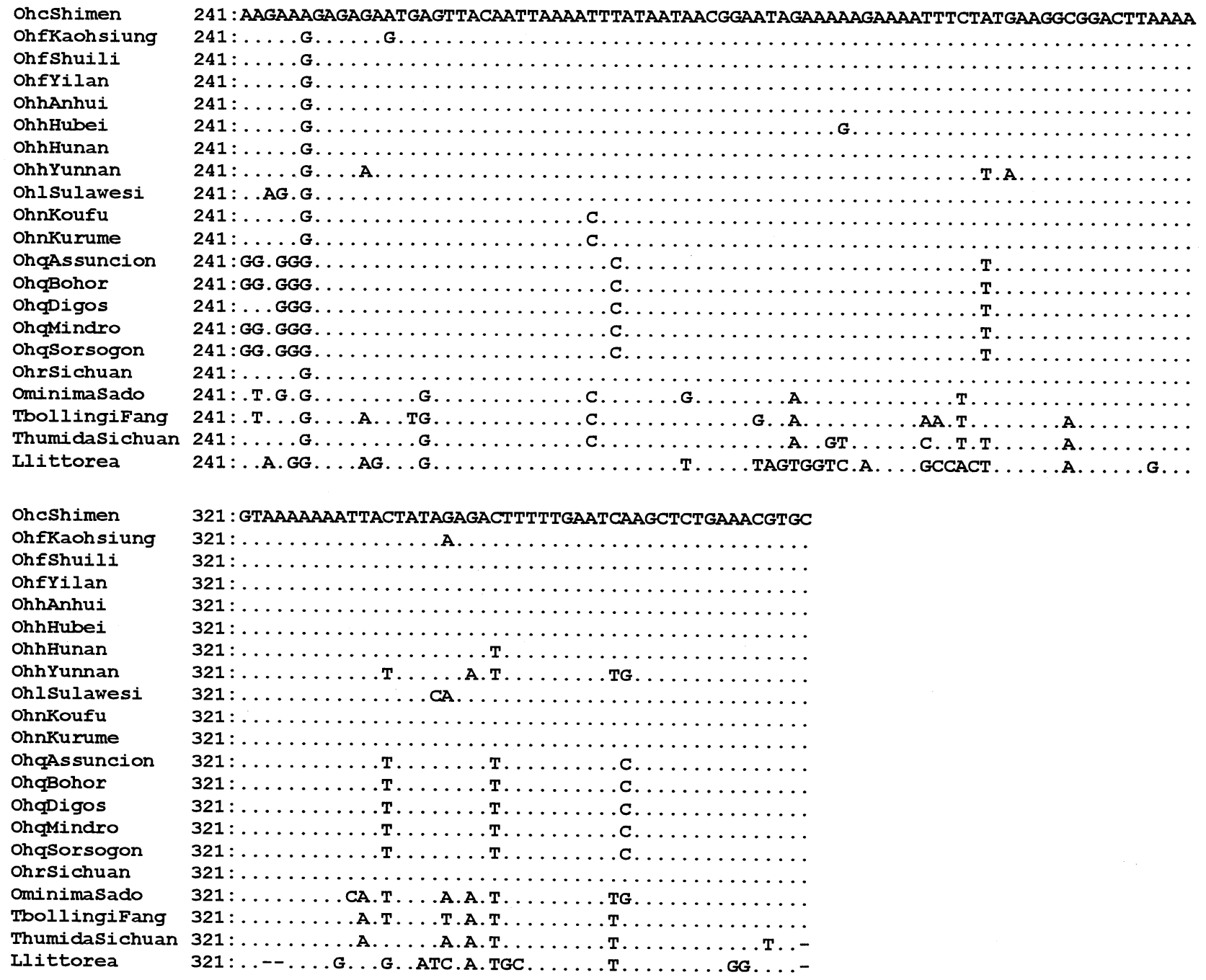

Fig. 2. Nucleotide sequence alignment of the $12 \mathrm{~S}$ ribosomal RNA gene in the mitochondrial DNA in the three genera, Oncomelania, Tricula and Littorina.

Table 2. Pairwise differences in nucleotide sequences of the $12 \mathrm{~S}$ rRNA gene among subspecies/species of the genus Oncomelania and Tricula.

\begin{tabular}{|c|c|c|c|c|c|c|c|c|c|c|}
\hline species/subspecies & O.h.hup. & .h.h.Yun & O.h.rob. & O.h.for. & O.h.chi. & O.h.nos. & O.h.lin. & O.h.qua. & O.minima & T.bollingi \\
\hline O.h.hupensis (excluding Yunnann) & $0.8^{*}$ & & & & & & & & & \\
\hline O.h.hupensis (only Yunnan)** & 4.2 & & & & & & & & & \\
\hline O.h.robertsoni & 0.7 & 4.4 & - & & & & & & & \\
\hline O.h.formosana & 1.1 & 3.7 & 1.0 & $1.3^{*}$ & & & & & & \\
\hline O.h.chiui & 0.0 & 4.6 & 0.8 & 1.3 & - & & & & & \\
\hline O.h.nosophora & 1.7 & 4.8 & 1.6 & 2.0 & 1.8 & $0.7^{*}$ & & & & \\
\hline O.h.lindoensis & 3.6 & 6.4 & 3.4 & 3.4 & 3.4 & 4.2 & $0.8^{*}$ & & & \\
\hline O.h.quadrasi & 5.1 & 6.4 & 5.3 & 5.0 & 5.0 & 6.1 & 6.2 & $0.7^{*}$ & & \\
\hline O.minima & 9.4 & 9.3 & 9.6 & 9.3 & 9.3 & 9.1 & 8.3 & 10.5 & - & \\
\hline T.bollingi & 10.0 & 10.2 & 10.2 & 10.4 & 10.4 & 9.9 & 9.8 & 11.7 & 8.8 & - \\
\hline T.humida & 10.7 & 12.1 & 11.0 & 10.7 & 10.7 & 10.5 & 10.8 & 12.5 & 9.0 & 9.9 \\
\hline
\end{tabular}

* : values for intra-subspecies

**: The Yunnan strain of O.h.h. was listed separately from the other strains, because it differed in a high degree from any other subspecies of O. hupensis. 
mum levels of nucleotide variations detected between pairs of species or subspecies for the $12 \mathrm{~S}$ rRNA gene are shown in Table 2. The values are expressed as pairwise differences in percentage. Nucleotide differences within the subspecies of $O$. hupensis were in general very low. However, in the case of $O$. $h$. hupensis, the intra-nucleotide difference was very large, because a Yunnan isolate of $O$. h. hupensis differed from all of the other isolates. On the other hand, differences among five of the subspecies, $O . h$. hupensis from China except for Yunnan, $O . h$. robertsoni, O. h. formosana, $O$. h. chiui and $O$. h. nosophora, were less than $2.0 \%$. Nucleotide differences between these 5 subspecies and $O . h$. lindoensis, or $O$. h. quadrasi or the Yunnan isolate of $O . h$. hupensis were larger, being about 3 to $6 \%$. Very large values of nucleotide differences (about 9 to 12\%) were obtained between different species.

As shown in Fig. 3, a phylogenetic tree of the snail hosts was constructed using the neighbor-joining method. Oncomelania hupensis subspecies are distributed among 4 groups. That is, four specimens of $O$. h. quadrasi from Philippines form a monophyletic clade. Oncomelania $h$. nosophora, O. h. hupensis, O. h. robertsoni, O. h. chiui and $O$. $h$. formosana form one group. Oncomelania $h$. lindoensis and $O$. h. hupensis from Yunnan make independent clades. In the meantime, O. minima, T. bollingi and T. humida also make independent clades, and they are genetically distant from each other as well as from all the subspecies of $O . h$. hupensis.

The sequence of mitochondrial 12S rRNA gene has been utilized to infer the phylogeny of various animals (Ko-

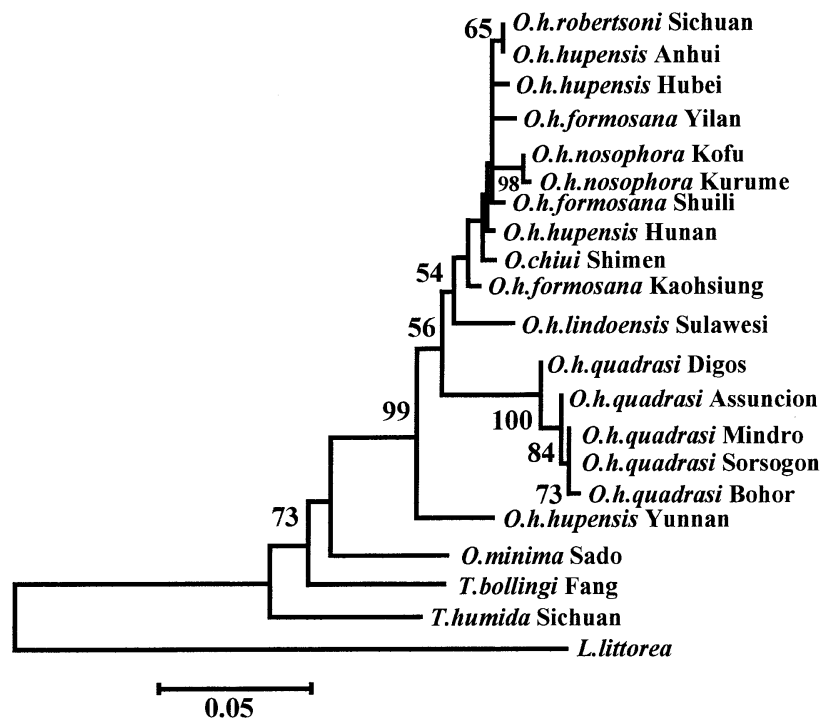

Fig. 3. A phylogenetic tree of the genus Oncomelania and Tricula, including the snail intermediate hosts of Schistosoma japonicum, inferred from 12S rRNA gene in the mitochondrial DNA using the NJ method. cher et al., 1989). Rumbak et al. (1994) examined the phylogenetic relationships among 11 species in the genus Littorina, which is a widely distributed marine gastropod, belonging to the same suborder Archaeotaenioglossa as the genus Oncomelania. In the case of the genus Littorina, nucleotide differences between European species and American species were about 3\%. And differences between subgenera in the genus Littorina were about $5 \%$ or more. In the present study, $O$. hupensis were distributed among 4 groups, and nucleotide differences among these 4 groups were 3 to $6 \%$. Although there is no reason to assume that rates of molecular evolution have been the same in Littorina as in the pomatiopsids, comparisons of the percentage differences between the two studies suggest that the subspecies in $O$. hupensis may require re-evaluation as suggested by Woodruff et al. (1988). Despite the wide geographic area involved, the genetic differences between the subspecies in Japan, Taiwan and China were very small. All of the examined snails in China were collected from the Yangtze basin except for that of Yunnan Province. In the glacial maxima, only approximately twenty thousand years ago (Wang and Sun, 1994), sea levels were much lower than now, the mouth of the Yangtze was considerably closer to Japan and Taiwan, and the Taiwan channel was dry land. This could explain the high levels of similarity among Japanese, Taiwanese and Yangtse basin samples.

It has been reported that genetic variation among $S$. japonicum populations in Asia, including China, the Philippines, Japan and Indonesia, is very slight (Bowles et al, 1993). However, we have shown that genetic variation among their intermediate host snails is quite considerable. Thus, our study supports the idea that $S$. japonicum has been recently introduced to many areas where it now occurs, and has been able to adapt to local strains of Oncomelania, as suggested in previous papers (Woodruff, 1988; Davis, 1992; Attwood et al., 2002).

Davis (1980) suggested that $S$. sinensium may constitute a species complex, because of geographical differences in snail host specificity. Our previous studies showed a large difference in egg sizes as well as in nucleotide sequence of $\mathrm{CO} 1$ between the two isolates of $S$. sinensium from China and Thailand, supporting Davis's hypothesis (Kawanaka et al., 1998; Agatsuma et al., 2000). The present result of a large distance value between their intermediate hosts may suggest coevolution between the hosts and parasites.

\section{ACKNOWLEDGEMENTS}

We would like to thank Associate Professor David Blair, James Cook University, and Associate Professor Joanna D. Hare, Kochi Medical School, for reviewing the 
manuscript. This study was partly supported by a Grant-inAid for Overseas Scientific Research (T. Agatsuma: 05041098) from the Japanese Ministry of Education (1993).

\section{REFERENCES}

1) Agatsuma, T., Iwagami, M., Liu, C.X., Saitoh, Y., Kawanaka, M., Upatham, S., Qui, D. and Higuchi, T. (2001): Molecular phylogenetic position of S. sinensium in the genus Schistosoma. J. Helminthol., 75, 215-221.

2) Attwood, S.W., Upatham, E.S., Meng, X.H., Qiu, D.C. and Southgate, V.R. (2002): The phylogeography of Asian Schistosoma (Trematoda: Schistosomatidae). Parasitology, 125, 99-112.

3) Bowles, J., Hope, M., Tiu, W.U., Liu, X. and McManus, D.P. (1993): Nuclear and mitochondrial genetic markers highly conserved Chinese and Philippine Schistosoma japonicum. Acta Trop., 55, 217-229.

4) Davis, G.M. (1980): Snail hosts of Asian Schistosoma infecting man: origin and coevolution. Malacol. Rev. Suppl., 2, 195-238.

5) Davis, G.M. (1992): Evolution of prosobranch snails transmitting Asian Schistosoma; coevolution with Schistosoma: a review. Progr. Clinical Parasitol., 3, 145-204.

6) Davis, G.M., Yi, Z., Hua, G.Y. and Spolsky, C. (1995): Population genetics and systematic status of Oncomelania hupensis (Gastropoda: Pomatiopsidae) throughout China. Malacologia, 37: 133-156.

7) Felsenstein, J. (1993) PHYLIP. Version3.5.1, University of Washington, Seattle.

8) Kawanaka, M., Sugiyama, H., Saito, Y., Habe, S., Upatham, E.S., Qui, D., Taguchi, N. and Agatsuma, T. (1998): Morphometric and molecular genetic comparisons of two geographic strains of Schistosoma sinensium isolated from Sichuan Province, China and North Thai- land. Proceedings of the 9th International Congress of Parasitology, Chiba, Japan. Monduzzi Internat., Bologna, 649-653.

9) Kimura, M. (1980): A simple method for estimating evolutionary rate of base substitutions through comparative studies of nucleotide sequences. J. Mol. Evol.16, 111-120.

10) Kocher, T.D., Thomas, W.K., Meyer A., Edwars, S.V., Påabo, S., Villablanca, F.X. and Wilson, A.C. (1989): Dynamics of mitochondrial DNA evolution in animals: amplification and sequencing with conserved primers. Proc. Natl. Acad. Sci. USA, 86, 6196-6200.

11) Nihei, N., Kanazawa, T, Blas, B.L., Saitoh, Y., Itagaki, H., Pangilinan, R., Matsuda, H. and Yasuraoka, K. (1998): Soil factors influencing the distribution of Oncomelania quadrasi, the intermediate host of Schistosoma japonicum, on Bohol Island, Philippines. Ann. Trop. Med. Parasitol., 92, 699-710.

12) Rollinson, D. and Southgate, V.R. (1987): The genus Schistosoma: A taxonomic appraisal. pp1-49. In: Rollinson, D. and Simpson, A.J.G. (eds). The biology of schistosomes from genes to latrines. Academic Press, London, UK.

13) Rumbak, E., Reid, D.G. and Thomas, R.H. (1994): Reconstruction of phylogeny of 11 species of Littorina (Gastropoda: Littorinidae) using mitochondrial DNA sequence data. Nautilus Suppl., 2, 91-97.

14) Wang, P. and Sun, X. (1994): Last glacial maximum in China: comparison between land and sea. Catena, 23, 341-353.

15) Woodruff, D., Staub, K.C., Upatham, E.S., Viyant, V. and Yuan, H.C. (1988) Genetic variation in Oncomelania hupensis: Schistosoma japonicum transmitting snails in China and the Philippines are distinct species. Malacologia, 29, 347-361. 